\title{
TRANSCENDING THE ELEMENTS: THE MEANING IN THE MIST AND STARS IN CHARLES DICKENS'S GREAT EXPECTATIONS
}

\section{ISABELLE STROMBERG}

$\mathrm{M}$ ist lies in soft quilts over the nighttime marsh landscape. The metallic and salty air is still- so still, in fact, that the air nearly vibrates with an

empty resonance. Shimmers of silvery stars flicker in the heavens above, gently covered up and revealed again by the swirling mist. The marsh is empty at this hour, or at least empty of the uproarious human hubbub that thrives miles away, in the otherworldly landscape of a bustling London night. While the marsh landscape may be devoid of humans, the land seems to breathe, expanding and contracting with profound inhales and exhales of moisture, and winking playfully through the glimmering stars.

The reader has been transported to the English countryside: that of the novel Great Expectations by Charles Dickens. The mist and the stars of the natural world permeate into both the plot and the characters of the novel. The main character, Pip, sees the world through a narrow perspective that is hindered by the heavy mists of his upbringing on the marsh. Pip's upper-class love interest Estella, on the other hand, exists in the metaphorically unattainable realm of stars. Dickens named his characters with intention, and we find clues about each character in their names. The Merriam Webster dictionary defines pip as "A small fruit seed," while stella stands for star in Latin. Here in our two lovers we see the duality of earth and sky, ground and heavens: an incorporation of the natural world into their personas that will be further explored. Pip finds himself rooted into the earth of his home like a seed and eager to sprout out of his husk. Or rather he should be rooted, were it not for his dissatisfaction with his home soil. On the other hand, Estella hovers unchanging and eternal, just out of reach in high society like a star. In the novel, we follow the evocative and often poignant adventures of young Pip, in his rise to fulfill the great expectations bestowed upon him by a mysterious benefactor. While Pip's journey embodies themes and symbols of romance, family, wealth, homeliness, and urban life, one particular theme holds particular opportunity for exploration: the natural world, as portrayed through the mist and the stars. Through observation of the mist and the stars, Dickens provides us with an insightful method that we can use to understand the role of perspective in the text.

Mist and fog are not new motifs in Dickens's work. Dickens is known to never do things once, both within a text and across his texts. For example, Dickens writes in 1836 in one of his very first publications, "Night:" from Sketches by Boz about this moist phenomenon, "But the streets of London... when the heavy lazy mist, which hangs over every object, makes the gas-lamps look brighter, and the

Meliora Vol. 1, Issue 1 
brilliantly-lighted shops more splendid, from the contrast they present to the darkness around." Even within the brief format of a sketch, Dickens integrates mist as an agent of scene-setting. The mist "hangs over every object," as if there is no escaping the reach of the pervasive dampness. Yet notably, instead of casting a gloomy edge upon the London cityscape, the mist actually "makes the gas-lamps look brighter." Aesthetically, the mist acts as fractals of reflective moisture that help to enhance the luminous gas-lamps. Dickens utilizes the mist to build contrast in the scene between the natural elements and the golden warmth of street lamps and the "brilliantly-lighted shops." In other words, the mist heightens the appeal of the indoors and the private, manmade sphere. Through this interplay between mist and artificial light, Dickens emphasizes that mist and the elements infiltrate our experiences inside and within urban settings, as well as in nature.

However, mist is not always a desirable symbol for Dickens. In fact, more often than not, the mist represents moments of dreariness and dismay. For example, in Oliver Twist, Dickens writes, “The mud lay thick upon the stones, and a black mist hung over the streets; the rain fell sluggishly down, and everything felt cold and clammy to the touch" (chapter XIX). In the span of one sentence, Dickens has assembled a lexicon of foggy language: "black mist," "rain," "cold," and "clammy." By employing varied and specific language around the fog, Dickens emphasizes that mist itself is a three-dimensional and complex feature of the environment that can be interpreted and perceived with subtly different meanings. Dickens continues to consider mist as a subject worthy of contemplation in Great Expectations, yet we can always return to his earlier work to discover that mist was a part of his repertoire far before the novel's release. The ephemeral mist takes on different connotations in different contexts, so Dickens's language and detail describing mist becomes especially noteworthy.

The stars are also not a novel theme in Dickens's work. Dickens was particularly intrigued by contemporary developments in the realm of astrology, and fittingly Great Expectations is considered his "Greatest work on stargazing" (Rainsford). However, we also see the appearance of stars in novels such as Bleak House, published in 1852. In the novel, Esther narrates her time getting to know the property: "At first [the unknown objects] were faintly discernible in the mist, and above them the later stars still glimmered" (chapter VIII). Even from this singular moment, we see the way in which Dickens sets up the mist and stars as opposite of each other, or at least complementary natural forces. The mist sinks heavy upon the earth, while the stars glimmer in the heavens above. In the context of Great Expectations, we will go on to see the way in which opposition to and overlap between the stars and mist comes to represent opposing and overlapping themes in the book such as travel and home and the relationship between Pip and Estella.

In the example of Bleak House, looking up at the stars becomes a symbol of perspective, or more precisely, the unifying human experience of looking up at the 
same stars that we know all people look up to. Esther goes on to narrate, "I looked up at the stars, and thought about travellers in distant countries and the stars THEY saw" (chapter XXIIX). In vaguely referring to "travellers in distant countries," Esther in fact alludes to her distant lover, Allen Woodcourt, who has been traveling in India. Even though Esther is far from Woodcourt in space, the stars make her feel closer to him in spirit. Esther feels some sense of camaraderie and intimacy with Woodcourt through the fact that they are both looking up at the same constellations. In this line, Dickens asks us to consider that regardless of who we are and where we are, there are some things that we see the same as one another. Dickens will later pick up this motif of perspective in the stars when Pip looks up and imagines (perhaps in a more morbid scene) what it would be like for a dying man to look at the same stars Pip sees: "I looked at the stars, and considered how awful it would be for a man to turn his face up to them as he froze to death" (43). The stars help characters to look outside of themselves, and remember that, in the grand scheme of things, they are part of something much larger than themselves.

In Great Expectations, the mist and marsh become a place for Pip to reflect on his place in the universe. However, Pip struggles throughout the text to see beyond himself, and instead opts to prioritize his own interests and social climbing. Pip tells the reader, 'I remember that at a later period of my 'time,' I used to stand about the churchyard on Sunday evenings when night was falling, comparing my own perspective with the windy marsh view, and making out some likeness between them by thinking how flat and low both were, and how on both there came an unknown way and a dark mist and then the sea" (87). Because Pip says this standing in a churchyard, this moment of reflective contemplation about his perspective becomes a sort of religious or spiritual experience for him. It may seem hopeful that Pip compares his own perspective with something outside himself, but in fact, he compares his perspective with the marsh only to find with dismay "how flat and low both were." Pip feels a sense of desolation within himself mirrored in the ominous "dark mist" before him. He also speaks to the "unknown way" that he feels in his own life and the natural landscape. It is telling, though, that this scene is a solitary moment for Pip in which he wallows in the "flat and low" trajectory of his futureyet he is hardly alone in the universal feelings of uncertainty and ambiguity that often accompany young adulthood. Perhaps if Pip could broaden his perspective through literal or metaphoric stargazing, he would come to realize that he is not alone in his very natural process of reflection.

As seen in the above scene, the mist is evoked in relation to uncertainty about Pip's future. A more distilled way to look at this phenomenon is that the mist represents not just uncertainty, but active confusion, concealment, and obstruction. In this spirit, it is worth considering the homonym of "mist" and "missed." As readers, we may consider, what is missed in the mist? What is concealed and hidden in the swirling moisture? Dickens phrases this succinctly as, "In the confusion of the 
mist" (19-20). The mist moves and swirls as if it is animated, and, in doing so, the mist evokes a strong sense of confusion for the hide-and-seek dynamic that is present throughout Great Expectations. When a character is hiding themselves, they often move into the mist. As Pip goes on a chase through the marshes, he narrates, "And then he ran into the mist, stumbling twice as he went, and I lost him" (20). Here, the mist absorbs Orlick like a cloak of invisibility. The moment that Orlick is absorbed into the mist, Pip considers him "lost." He knows it is hopeless to feel his way through the dark and thick mist; the mist is more powerful and mysterious than Pip can compete with. Orlick himself can be considered a creature of the mist, as he is never made to pay for his crimes, and never fully grasped in motive or flesh.

In the spirit of hiding, just as others can hide in the mist, so can Pip. The scene in which Pip meets the convict, he notes, "I indicated in what direction the mist had shrouded the other man... The last I heard of him, I stopped in the mist to listen, and the file was still going" (22). In these quotes, the mist presents Pip with an opportunity to observe without being seen, which, for young Pip, is really the main source of his self-directed education. Rather than attending school, Pip learns about the world around him through careful observation, which we see evidence of in his astute narration. Just as the mist conceals others, it also lets Pip sink into oblivion so that he can observe from afar. The mist allows Pip the anonymity and invisibility to gain one more small piece of information from the convict - the ominous sound of the scraping file.

The mist also has a way of shifting Pip from the seeker to the one being sought. As he is running away from his time with Magwitch, the convict in the opening of the novel, Pip narrates, "The mist was heavier yet when I got out upon the marshes, so that instead of my running at everything, everything seemed to run at me. This was very disagreeable to a guilty mind" (19). The mist upends reality, and evokes a surreal, almost dream-like state for young Pip. It sounds as if Pip is in a nightmare, in which instead of him running at everything, everything runs at him. Instead of being the active seeker, Pip becomes the guilty victim being sought.

While the mist represents confusion and concealment, the stars represent clarity of thought and emotional transparency. As Joe is speaking with Biddy, the text reads: “'Are you quite sure, then, that you will come to see [Joe] often?' asked Biddy, stopping in the narrow garden walk, and looking at me under the stars with a clear and honest eye" (216). The starlight here acts as a luminary light of clarity. The starlight correlates with that which is "clear" and "honest." Biddy is discerning and perceptive towards Pip, and she picks up on the reality that Pip may not come to see Joe as often as he claims. Typically, we see starlight likened to Estella, highlighting her aloof and inaccessible nature. Yet here, the starlight emphasizes the genuine inquisition and perceptiveness of Biddy. Perhaps, then, it is not that the stars are aloof and inaccessible, but rather that they illuminate the true nature of a character.

Meliora Vol. 1, Issue 1 
Just as the presence of stars means clarity, the lack of stars means uncertainty. From Pip's first time leaving Joe at home to go play with Miss Havisham, we see the presence of stars correlating with clarity, even if what they reveal is that full clarity has yet to arrive. Pip recalls, "I could at first see no stars from the chaise-cart. But they twinkled out one by one, without throwing any light on the questions why on earth I was going to play at Miss Havisham's, and what on earth I was expected to play at" (45). The stars throw light on questions, meaning that they metaphorically and literally illuminate Pip's uncertainty. Even before Pip has arrived at Miss Havisham's, we see the correlation between Miss Havisham and the stars, a prelude to the arrival of Estella into the plot.

Mist is not only a weather or aesthetic-based phenomenon-it is also a symbol of emotion. As Dickens writes of Oliver in Oliver Twist, "A mist came before his eyes; the cold sweat stood upon his ashy face; his limbs failed him; and he sank upon his knees" (chapter XXII). Here, the word mist is synonymous with tears, or at least a misting up of the eyes. Just as infinitely small particles of moisture make up the broad scope of mist across the marsh landscape, they also comprise the single tear that may fall from one's eye. There is a certain unity, therefore, between the mist of the landscape and the emotional misting up of the eye. The mist is also personified as sadness through the inclusion of a goblin. Dickens writes, "It was a rimy morning, and very damp. I had seen the damp lying on the outside of my little window, as if some goblin had been crying there all night, and using the window for a pocket-handkerchief' (19). While this simile can be read as an endearing and animating comparison of the weather to a goblin, it also speaks to the way that the dampness reflects an emotional release for nature. This analogy also serves as a reminder of the importance of experiencing the full range of human emotions. Just as each piece of nature is important, each piece of our emotional landscape is also important. As Pip leaves home for the first time, he finds himself in tears and admits, "Heaven knows we need never be ashamed of our tears, for they are rain upon the blinding dust of earth, overlying our hard hearts. I was better after I had cried than before, - more sorry, more aware of my own ingratitude, more gentle" (124). Pip's tears act as a flood, cleansing his "hard heart" and filling him with a greater sense of gratitude and gentleness. Through Pip's narration of tears, Dickens highlights for the reader that the grief, glumness, and release of human emotion through tears is not something to be avoided; rather, it is precisely when we lean into our sadness that we can begin to move on and heal.

We also see the way in which tears act as an emotionally unifying force between Pip and Estella at the end of the novel. The text reads, "The silvery mist was touched with the first rays of the moonlight, and the same rays touched the tears that dropped from her eyes" (357). Here, Estella embodies a symbolic unity between her and Pip. If the mist, the moisture, and the tears represent Pip, and the heavens, stars, and silvery moonlight above represent Estella, then the merging of the silvery

Meliora Vol. 1, Issue 1 
mist with tears and the moonlight reflects the moment of union between these two lovers. In the final lines of the novel, this moment of union through tears proves to be especially poignant, a rare instance of intersection between the emotional states of Pip and Estella.

As the stars represent the divine hovering just out of reach, the marsh mist is often associated with Pip's inescapable sense of being bound to home. The mist mirrors the marsh, and the marsh mirrors the mundanity and familiarity of Pip's home from which he so desires to break free. Yet, even when Pip does break free from the misty marsh, he finds that he still holds complex and regretful feelings towards his departure from home. As Pip explores the London streets, he narrates, "Yet in the London streets so crowded with people and so brilliantly lighted in the dusk of evening, there were depressing hints of reproaches for that I had put the poor old kitchen at home so far away" (146). Just as the marsh and mist represent home, the London street lamps become manmade stars in the urban landscape, representing just how far Pip really is from home. The mist has the potential to enhance the city lights, and fuse the natural world with the urban humanity of the city. The London streets move fast, and the reader can nearly imagine the clatter and vivacity of the "crowded" streets—a far cry from Pip's peaceful marsh home. Pip holds this contrast in his mind, as we see that he feels "depressing hints of reproaches" for his home, even when he should be distracted by the brilliant motion of the London streets that he has strived so hard to arrive at.

In stark contrast to the "brilliantly lighted" scene of London, the lights in Pip's hometown are stagnant and heavy due to the marsh mist. As Dickens highlights in the novel, Pip's home and the surrounding area by the marsh are often layered in a thick layer of mist. In this spirit, when Pip and Mr. Wopsle go out in town together, Pip narrates that they, "Found a heavy mist out, and it fell wet and thick. The turnpike lamp was a blur... its rays looked solid substance on the fog" (94). Usually light flashes, glimmers, and wavers as an agile element like it does in the big city of London. While the mist enhanced the beauty and appeal of the lamps in "Night:" from Sketches by Boz, Pip's perspective leads the mist to enhance his sense of feeling stuck in his life. With the presence of the "heavy mist," even the light becomes weighed down and "solid." This detail that even beams of light are weighed down by the mist emphasizes Pip's mental state; absolutely every aspect of home is heavy for Pip, as if it is stuck in inescapable amber.

Dickens frequently employs the motif of mist rising as a way to signify important moments in the novel, especially moments that pertain to Pip seeing the world anew in his coming-of-age journey. As Pip sets off for home for the first time to pursue his great expectations, he writes, "The village was very peaceful and quiet, and the light mists were solemnly rising, as if to show me the world" (124). Dickens imbues this line with a theatrical metaphor. Pip stands front and center on the stage, looking over a vast landscape before him. The mists act as a stage curtain to the play 
that is Pip's life. As the curtain of mists rise, Pip is invited to look ahead to the following acts of his adventure. However, Pip takes this moment that should stand for broadened perspective and turns himself into the protagonist. There is a certain irony to the fact that the mists are rising-supposedly giving Pip a wider sense of scope and visibility upon the world-yet Pip narrates the mists rising from a fundamentally self-centered place. Pip speaks of the mist rising "as if to show [him] the world." The mists are not rising due to the sun evaporating the moisture, or for all the people in the town who will wake to find mist floating away from the earth in foggy tendrils. Rather, the mists rise for Pip, and Pip only. As readers, we are drawn further into Pip's adventure, while also rooting for him to mature and expand the scope of his awareness.

Dickens continues the motif of mist rising when he writes, "The mists had all solemnly risen now, and the world lay spread before me" (125). Similar to the previous except, Dickens includes that mists that are rising "solemnly." The word "solemnly" evokes an action done in a serious, earnest, and dignified manner. The fact that the mists rise solemnly suggests that this is not a scene to be taken lightly. Rather, the rising of the mist holds all the weight and importance that accompanies leaving home and growing up for Pip. Pip's rise into adulthood, or at least young adulthood, is not a lighthearted and easygoing maturation. Rather, Pip's coming of age aligns with the solemn nature through which the mists are described. Later in the novel, Pip recalls, "I turned my head aside, for, with a rush and a sweep, like the old marsh winds coming up from the sea, a feeling like that which had subdued me on the morning when I left the forge, when the mists were solemnly rising" (191). Even with the passage of time, Pip remembers the mists rising as particularly solemn. He also notes that the mists were rising at the moment that Pip left the forge- the moment that he said goodbye to Joe, his apprenticeship, and the routines of home. The solemn rising of the mists closely associates itself with Pip leaving the marshes, leaving the forge, and growing up through gaining independence, emphasizing the profound importance that Pip applies to his own coming-of-age journey.

Of course, much of the allure of Pip's new life is due to the fact that it gets him one step closer to the love of his life, Estella. Taking a break from the heavy and low-lying mists, we turn our heads up to the stars in the sky. Perhaps the most relevant role of stars in Great Expectations is through the character of Estella herself. As noted earlier, the name Estella shares the Latin word for star, "stella." Just like a star, Estella literally shines in the eyes of Pip. After a period apart, Pip writes, "Estella looked more bright and beautiful than before, and I was under stronger enchantment" (184). In the natural world, the adjectives "bright" and "beautiful" would often be compared to elements of the heavens, be it the sun, a bright full moon, or the twinkling stars. Here, the brightness and beauty of Estella pull Pip into her orbit of attraction. Yet just like a body orbiting the sun, Pip will keep spinning 
and spinning around because of the gravitational force of Estella, never to truly make contact.

Here, it is helpful to invoke the words of a leading figure in thought on the natural world: the Transcendentalist Ralph Waldo Emerson. Our discussion of mist and the stars in Great Expectations can be further explored through a Transcendental lens. Just as this essay seeks to analyze the symbology, emotions, and deeper meaning behind the mist and stars, the Transcendentalists sought to find deeper meaning in the natural world as well. Even if Emerson and Dickens never read each other's work, there is significant overlap in the way that each author treats the natural world with meaning and detail in their work. Furthermore, Emerson explains why we are so drawn to the stars - and his explanation fits almost perfectly with Pip's experience of being drawn to Estella. We can utilize Emerson's words to better understand the mind of young Pip. Emerson writes, "The stars awaken a certain reverence, because though always present, they are inaccessible." If we replace the word "stars" here with the idea of Estella, this line reads: "Estella awakens a certain reverence (in Pip), because though she is always present, she is inaccessible." It is as if Emerson himself could read Pip's mind about Estella; Estella is "always present" in Pip's consciousness, though she is fundamentally "inaccessible" to him as a committed and available lover. Therefore, she evokes a strong reverence in Pip's heart. Pip narrates this reality when he declares to Estella:

Out of my thoughts! You are part of my existence, part of myself. You have been in every line I have ever read since I first came here, the rough common boy whose poor heart you wounded even then. You have been in every prospect I have ever seen since,- - on the river, on the sails of the ships, on the marshes, in the clouds, in the light, in the darkness, in the wind, in the woods, in the sea, in the streets. You have been the embodiment of every graceful fancy that my mind has ever become acquainted with. The stones of which the strongest London buildings are made are not more real, or more impossible to be displaced by your hands, than your presence and influence have been to me, there and everywhere, and will be. Estella, to the last hour of my life, you cannot choose but remain part of my character, part of the little good in me, part of the evil. (272)

Evidently, Estella has intertwined herself into every last thought, perception, and prospect of Pip's existence. Just like starlight itself, Estella is unshakable. Even in the blue skies of daylight, when one assumes the stars are extinguished, they are in fact still in the sky above us and just invisible to the naked eye. In the same way, Estella is always in the background of Pip's consciousness, "in the light, in the darkness," in the good times and the bad, shining into every aspect of Pip's being. Yet this is where Emerson's quote becomes so fitting; Estella is indeed "always present" in Pip's being, yet she is "inaccessible" just like the stars are to mortals. We can admire the stars from afar, reveling in their twinkling glory, yet like Icarus, if we get too 
close to the sun, we will fall. Just as humans cannot break the laws of gravity and thermodynamics to access the stars, Pip is fully incapable of assessing the aloof and emotionally unavailable Estella.

As one may assume, the pressing immediacy and presence of Estella in Pip's mind does not turn out to be sustainable nor healthy. Estella holds a greater space in Pip's mind than in his actual day-to-day life, as if she is more so an idealized force of nature than an actual human. Pip explains, "Estella was so inseparable from all my restlessness and disquiet of mind, that I really fell into confusion as to the limits of my own part in its production" (207). This word choice of "inseparable," "restless," and "confusion" evoke much more of an infatuation than a healthy and sustainable romance. Estella has an enormous sway on Pip's sense of self, as if she herself is the gravitational pull around which Pip orbits.

Given the close association between the stars and Estella, the stars also come to represent possibility for Pip. When Pip feels stuck and offended by Biddy and Joe discussing his departure, he narrates, "I would get up and look out at the door; for our kitchen door opened at once upon the night, and stood open on summer evenings to air the room. The very stars to which I then raised my eyes, I am afraid I took to be but poor and humble stars for glittering on the rustic objects among which I had passed my life" (113). Pip's life thus far has been defined by "rustic objects," yet at the beginning of his journey to great expectations he yearns for something ambitious amongst the stars. When Pip is at home, the stars and all the possibilities they represent are a mode of escaping and a place to put hope. As explored here, the stars signify looking outwards and forwards for Pip, while the mist is about turning inwards. The stars and Estella indicate striving, climbing into high society, and looking ahead, while the mist and Pip's marsh are about home, comfort, stagnancy, and reflection.

Yet the possibility of the stars is not always a positive-it can also be framed as fantastical escapism. Towards the end of the novel, when Pip has been abducted by Orlick, Orlick says menacingly, "Now... I've got you," to which Pip exclaims, "Unbind me. Let me go!” Orlick returns, "Ah! ... I'll let you go. I'll let you go to the moon, I'll let you go to the stars" (315). Orlick almost threatens Pip with the possibility of going to the stars, as they both know this is an illogical and impossible destination. The stars then become a place of the ideal, in which pain and suffering are alleviated and safety and protection reign. Only in death are the stars a place to which one can escape, and, amidst all the disagreement and turmoil between Orlick and Pip, this is one thing that they can agree upon. Everyone finds a certain magic and intrigue in the stars, regardless of who they are.

According to the philosopher Aristotle, stars are made of a material called quintessence, the fifth element that is shared by angels and holy bodies. Quintessence was believed to have had no matter to it-it is pure energy and light. Quintessence is one of the most powerful substances for its spiritual, unworldly 
grandeur and its ability to remain pervasive yet untouchable, like Estella. In Great Expectations, this divine spirit of the stars comes across in Pip's intense admiration for the star of Estella. As Pip states, "Estella looked more bright and beautiful than before, and I was under stronger enchantment" (184). Estella's "enchantment" has a profound impact over Pip, to the extent that Estella rules him with her star-like powers. Notably, Pip is not able to touch Estella or present his compliment directly to her face; Estella remains inaccessible like the stars, but she still has the power to dazzle him with her aloof quintessence.

The stars are the closest thing we have in proximity to the heavens, and they take on a spiritual quality in relation to their position and awe-inducing vastness. It is again thought-provoking to consider a Transcendental perspective, since the Transcendentalists were especially in touch with the inherent divinity that we find in nature. Even though Dickens does not explicitly address the spirituality of the stars, Dickens's careful and descriptive language of describing the heavens at least suggests him to be an admirer of the heavens, a sentiment that critic Dominic Rainsford confirms. As readers, we can use Transcendental language about the wonder and beauty of stars to gain a deeper understanding of the wonder that Pip feels for Estella and her beauty. Emerson articulates this sense of wonder in his essay Nature when he writes, "But if a man would be alone, let him look at the stars." In the same sense, once Pip meets Estella, Pip is alone for life. Emerson continues, "The rays that come from those heavenly worlds, will separate between him and what he touches. One might think the atmosphere was made transparent with this design, to give man, in the heavenly bodies, the perpetual presence of the sublime... But every night come out these envoys of beauty, and light the universe with their admonishing smile." The language of "heavenly bodies" and "sublime" highlights the sense of the divine that we can find in nature, especially under a night sky lit up by twinkling stars. More importantly, this divine worship of the heavens parallels the divine worship that Pip feels towards Estella. Pip puts his spiritual infatuation with Estella succinctly when he admits:

The unqualified truth is, that when I loved Estella with the love of a man, I loved her simply because I found her irresistible. Once for all; I knew to my sorrow, often and often, if not always, that I loved her against reason, against promise, against peace, against hope, against happiness, against all discouragement that could be. Once for all; I loved her none the less because I knew it, and it had no more influence in restraining me than if I had devoutly believed her to be human perfection. (179)

Here, the word "devoutly" evokes Pip's intense and unwavering commitment to Estella. If Estella is in fact the human embodiment of a star, then Pip's devotion could be read as Transcendental-he worships the divine in nature. The Transcendentalists believed in the inherent divinity of nature, and the human 
potential for connection to the divine through immersion in the elements. However, the Transcendentalists also preached a sense of interconnectivity and selflessness that we find in nature, a phenomenon described by Ralph Waldo Emerson as a transparent eyeball. In the above quote, Pip clearly emphasizes a sense of selfishness over selflessness, making his devotion to the star of Estella decidedly unTranscendental because it places him further from-not closer to-other people. Pip repeatedly employs the "I" pronoun; his declaration of love for Estella is more about him than her. Similar to his inward focus with the rising mist, Pip struggles to broaden his perspective to center others than himself. In addition, Pip frames this declaration of love as a sort of rebellion-he repeats the word "against," as if his love defies all odds rather than aligns with what is natural. Estella's star-like qualities levitate her out of the quotidian, earthly, and rational world in which Pip was raised, and instead transport her into the realm of the eternal, heavenly, and spectacular that Pip finds so very alluring.

As readers, it may be difficult to understand how_or why_Pip could feel so drawn to someone so distant. However, we can better understand the relationship between Estella and Pip through a scene in which Pip describes an imaginary scene taking place on a frigid winter's night. He writes, "A man would die to-night of lying out on the marshes, I thought. And then I looked at the stars, and considered how awful it would be for a man to turn his face up to them as he froze to death, and see no help or pity in all the glittering multitude" (43). In this scene, Pip reminds us that beauty becomes even sharper in the presence of pain. This is because there is wonder in discrepancy; the more lowly Pip sees himself to be, the more remarkable Estella becomes in his eyes. Just as this hypothetical man dies, the discrepancy between his freezing to death and the magnificent stars becomes all the more great. There is something cruelly beautiful about this scene that Pip imagines: a man dying in the presence of astounding beauty, yet the beauty of the stars can provide him with "no help or pity." The stars, though dazzlingly beautiful, almost taunt the man's lowly mortality with their eternal shine. The stars have no pity for this hypothetical dying man, just as Estella has no pity for Pip. She says of her heart, "I have no softness there, no-sympathy_-sentiment—nonsense" (183). Just as the stars taunt this hypothetical dying man, Estella's taunts Pip with her inaccessible nature, even as he remains in awe of her glittering allure. Pip is dying under Estella's glitter.

The scene in which Pip imagines a man freezing to death under the stars also provides Dickens with a place to emphasize the stars as a symbol of connecting ideas. As critic Dominic Rainsford writes of this scene of Pip imagining dying under the stars, "This is a crucial moment for Pip, insofar as it links his pity for Magwitch, whom he has no expectation of seeing again, with his own exposure, the following day, to the glittering and freezing Estella, who makes him into a new kind of helpless viewer of the heavens." Through the motif of the stars alone, Dickens has pulled together both Pip's views of Magwitch and his views of Estella. Rainsford's phrase 
"helpless viewer of the heavens" describes Pip's view towards Estella particularly aptly. Pip is eager to connect to Estella, but helpless when it comes to fulfilling that dream. Rainsford also speaks to the convict, Magwitch, who Pip "has no expectation of seeing again." Imagining looking up at the stars evokes a melancholic sense of loss for Pip, in which he realizes that the convict may be a mere figment of his memory from there on. This rich scene in which Pip envisions a dying man speaks to the connective nature of the stars-pulling together Pip's imagination, his pity for Magwitch, his infatuation with Estella, and the ultimate power of the heavens above.

Evidently, Estella and Pip struggle to connect throughout the novel. These two characters find themselves as far apart as the mist on the marshes from the stars in the heavens. It is perhaps only in the last scene of the novel that we see this dynamic change. As Dominic Rainsford explains, “The 'star' of Pip's life, Estella, fails to warm and comfort the protagonist-except, perhaps, in the last pages of the novel." It has been a long wait to the last pages of the novel, and any semblance of warmth and connection that we find between Pip and Estella in the final pages feels well-deserved after years of heartbreak and disconnect.

As Pip and Estella meet in the evening, the reader arrives at the evening stage of the novel. One of the final lines reads, "A cold silvery mist had veiled the afternoon, and the moon was not yet up to scatter it. But, the stars were shining beyond the mist, and the moon was coming, and the evening was not dark" (357). Through this depiction of the landscape, Dickens continues to emphasize the importance of the mist and the stars in the closing of the novel. However, the ending of the novel leaves an ambiguous conclusion as to the future of Pip and Estella. In a more optimistic reading that anticipates their union, we could cite that the text reads: "the evening was not dark," suggesting that even in the impending night, the mood of the scene holds some glimmers of hope. Dickens also writes that "the stars were shining beyond the mist," as if the stars and mist are in different realms yet still manage to coexist and complement each other beautifully. This dynamic can be paralleled in the future of Estella and Pip's relationship; they may exist in different realms, or social classes, but the reader may be left hopeful that they will find a way to coexist and complement each other in their lives. Estella's starry heavens mirror the elusive upper class, while Pip's misty realm of the marshes mirrors the working class - yet in this moment of closure, they co-exist. Furthermore, Dickens writes that a silvery mist had "veiled" the afternoon, evoking the matrimonial connotations of a veil to a wedding ceremony. While Dickens does not present the reader with an explicit statement on the future of Pip and Estella's relationship, this moment of veiled union between the mist and stars could suggest, if not marriage, a future of increased unity and peace.

However, not all who read Great Expectations anticipate a future for Pip and Estella. The poignant last line of the novel reads, "I took her hand in mine, and we went out of the ruined place; and, as the morning mists had risen long ago when I 
first left the forge, so the evening mists were rising now, and in all the broad expanse of tranquil light they showed to me, I saw no shadow of another parting from her" (358). Here, Pip says not once, but twice, that the mists have risen and are rising. In alignment with our previous reading of the mists rising, this line strongly lends itself to an indication that Pip has come of age, or sprouted from his original "seed" state. Yet given that the mists are rising in the present tense as well, we are led to believe that Pip still has more growing up to do, and some disillusionment to shake from his consciousness. The author William Sharpe writes of the ending: "Dickens leaves us with a shadow of an ending. But whether Dickens speaks of no shadow parting or no friends parting - and the two can overlap — the operative word is 'no.' And when there are no more shadows that look ahead, our expectations come to an end, along with the narrative." In a sense, the answer to whether or not Pip and Estella end up together has no bearing on the novel itself. As Dickens so artfully emphasizes throughout the novel, the meanings of mist and stars are not fixed, concrete, or conclusive. Rather, the mist and the stars serve as an excellent metaphor for the reality of ambiguity that settles into the relationship between Pip and Estella in the final pages.

In imbuing the mist and stars of Great Expectations with such meaning and depth, Dickens presents the reader with a gift of perspective. We may not always have the words and pages of the novel in front of us-but we always have the stars above us and the gentle mists rising from the earth. What we have learned from the novel, then, we can recall as we immerse ourselves in the elements of the world around us. As we go off on our own journeys and pursue our own expectations, Dickens invites us to look to the mist and stars as ways of conceptualizing our relationships to ourselves, our homes, our loved ones, and our sense of the divine in nature.

\section{WORKS CITED}

Dickens, Charles. "Bleak House." The Project Gutenberg EBook, Bleak House, by Charles Dickens, www.gutenberg.org/files/1023/1023-h/1023-h.htm.

Dickens, Charles. Great Expectations. Edited by Edgar Rosenberg, Norton Critical Editions, 1999.

Dickens, Charles. “Oliver Twist.” Oliver Twist OR THE PARISH BOY'S PROGRESS by Charles Dickens, www.gutenberg.org/files/730/730-h/730h.htm.

Dickens, Charles. "Sketches by Boz/The Streets - Night." Sketches by Boz/The Streets - Night - Wikisource, the Free Online Library, en.wikisource.org/wiki/Sketches_by_Boz/The_streets_-_night. 
Emerson, Ralph Waldo. "Nature." The Project Gutenberg EBook of Nature, by Ralph Waldo Emerson, www.gutenberg.org/files/29433/29433-h/29433h.htm.

Rainsford, Dominic. “The Dickens Universe: Gazing at the Heavens.” E-Rea Revue Électronique d'Études Sur Le Monde Anglophone, Laboratoire D'études Et De Recherche Sur Le Monde Anglophone, 15 June 2016, journals.openedition.org/erea/4962.

Sharpe, William. “'Look Elsewhere': Literal Foreshadows in English Literature."

Miranda. Revue Pluridisciplinaire Du Monde Anglophone / Multidisciplinary Peer-Reviewed Journal on the English-Speaking World, Université Toulouse 2 - Le Mirail, 1 Oct. 2013, journals.openedition.org/miranda/3467.

ISABELLE STROMBERG, Barnard College '21, is an English major with a concentration in film. She is especially interested in depictions of the natural world in literature. In addition, Isabelle enjoys filmmaking and exploring the intersection of narrative and visual arts. 